\title{
Strategy Instruction and Attributional Beliefs in West Germany and the United States: Do Teachers Foster Metacognitive Development?
}

\author{
Beth E. Kurtz AND Wolfgang Schneider \\ Max Planck Institute for Psychological Research, Munich
}

AND

\section{Martha Carr, John G. Borkowski, and Elizabeth Rellinger University of Notre Dame}

\begin{abstract}
Previous research has shown German children to be morc strategic on sort-rceall memory tasks than their American age-mates, and to show fewer effort-related attributions. We conducted this study to determine if those differences are due to systematic differences in the strategy instruction and attributional beliefs of German and U.S. teachers, and to explore metacognitive instructional practices in the two countries. Teachers responded to a questionnaire that inquired about their use of strategy instructions, fostering of reflective thinking in pupils, sources of children's learning problems, and modeling of metacognitive skills such as monitoring. The second part of the questionnaire asked about the reasons underlying children's academic successes and failures. German teachers reported more instruction of task-specific strategies, while American teachers showed more effort-related attributions. The types of strategies instructed and types of learning problems most frequently described varied across the two countries, and also according to how many years the teachers had taught. Results were discussed regarding their implications for metacognitive developmental theory, particularly regarding culture and other environmental influences on the development of controlled processing. 1990 Academic Press, Inc.
\end{abstract}

Children's cognitive development in the early elementary years is marked by an increasing sophistication in their use of strategies as well as their metacognitive knowledge about strategies and executive processes such as monitoring (Neimark, 1976; Ornstein, Baker-Ward, \& Naus, 1989; Schneider \& Pressley, 1989). In contrast to preschoolers, children in the middle- and upper-elementary grades effectively use categorization strategies (Justice, 1985), elaboration (Pressley, 1982), and reading strategies (Byrd \& Gholson, 1985; Myers \& Paris, 1978). Relatedly, older children illustrate superior verbalizeable metacognitive knowledge and

Beth Kurtz is now at the University of North Carolina and Martha Carr is now at the University of Georgia. Correspondence regarding this article should be addressed to Beth Kurtz at the Department of Psychology, University of North Carolina, Davie Hall, Chapel Hill, NC 27599-3270. 
monitoring skills (Kreutzer, Leonard, \& Flavell, 1975; Schneider, 1985; Schneider \& Pressley, 1989).

Although relatively little is known about the factors associated with the emergence of these strategies, one important influence on children's strategy and metacognitive development is presumed to be the instruction they receive from teachers and parents. The purpose of this project was to examine teachers' reported instruction of strategies and metacognitive knowledge in the classroom, as well as their attributional beliefs about the reasons underlying children's academic successes and failures.

\section{Teachers' Strategy Instruction}

Recent comprehensive models of "good" strategic functioning have included strategy, metacognitive, and motivational components (Borkowski, Carr, Rellinger, \& Pressley, in press; Pressley, Borkowski, \& Schneider, 1987a; Pressley, Goodchild, Fleet, Zajchowski, \& Evans, 1989). Efficient learners have multiple strategies at their disposal, including task-limited strategies that can be used only in very specific situations, and general strategies such as checking, outlining, and planning, which are applicable across domains (Pressley et al., 1989). Good strategy users possess accurate metacognitive knowledge about when, where, and why to apply specific strategies, including information about how to flexibly adapt them to new task demands. Finally, effective learners possess adaptive motivational beliefs about their own abilities and other factors that influence performance (Borkowski et al., in press; Pressley et al., 1987a; Pressley et al., 1989).

To date, most of the research focusing on the instruction of strategies, metacognition, and motivational beliefs has concerned teachers' strategy instruction. In a series of research projects, Moely and her colleagues have found that elementary school teachers vary widely in the amount of strategy instruction they provide; that instruction is tailored to the pupil's age (e.g., rationales for strategy use are given more frequently to older than to younger pupils); that children from high-strategy-instruction classrooms benefit more from strategy training on an experimental task than children from low-strategy-instruction classrooms; and that teachers view differential strategy use as an important source of individual differences in achievement (Moely, Hart, Leal, Johnson-Baron, Santulli, \& Rao, 1986a; Moely, Hart, Santulli, Leal, Johnson, Rao, \& Burney, 1986b; Moely, Hart, Santulli, Leal, Kogut, McLain, Zhou, \& Johnson, 1989; Moely, Leal, Pechman, Johnson, Santulli, Rao, Hart, \& Burney, 1986c).

Teachers influence cognitive development and school achievement not only through explicit strategy instruction, but also through overt and subtle messages about their perceptions of children's abilities, and their 
attributional theories about other factors that influence achievement. For instance, in a 4-year longitudinal study of British elementary pupils, Crano and Mellon (1978) found that the influence of teachers' expectations on student achievement was much stronger than the reverse relationship. Teachers' attributional theories about achievement and their achievement expectancies for particular students influenced the amount of praise and criticism they gave children as well as their amount of intimacy and power-sharing (Grant \& Rothenberg, 1986; Parsons, Kaczala, \& Meece, 1982). These factors, in turn, affected children's achievement expectations, effort expenditure, and resulting achievement.

Metacognitive instruction-including information about the utility of strategy use in improving learning efficiency, checking and monitoring skills, and the importance of tailoring strategies to task demands-is especially important for the young child's cognitive and metacognitive development. However, little is known about teachers' direct metacognitive instruction. Research on teachers' perceptions has indicated that teachers make reasonably veridical predictions of children's strategic capabilities, but not of their metamemory, monitoring, or control skills, and that teachers' metacognitive evaluations of children are biased by the children's achievement levels (Carr \& Kurtz, 1989; Moely, Santulli, \& Rao, 1985). Thus one major purpose of this project was to examine teachers' metacognitive instruction, and relatedly, their awareness of and responsiveness to children's learning problems. We were interested in the extent to which teachers modeled efficient learning behavior, including metacognitive instruction about ways to deal with particular learning problems.

\section{Cultural Differences in Teaching Practices}

Because characteristics of the environment such as parents' and teachers' instructions influence development, and because these environmental factors vary in different lands and among different peoples, culture plays a crucial, mediating role in the process of human development (Cole, 1988; Wagner \& Paris, 1981). For instance, a considerable body of research has recently documented how cultural differences between Japan and the United States result in contrasting attributional theories in the two countries, with resulting implications for children's achievement motivation (Holloway, 1988; Stevenson, 1988).

Our research has revealed systematic differences in the attributional beliefs and strategic behaviors of German and American children (Carr, Kurtz, Schneider, Turner, \& Borkowski, 1989; Kurtz, Schneider, Borkowski, Carr, \& Turner, 1989; Schneider, Borkowski, Kurtz, \& Kerwin, 1986). In brief, the results of this work have indicated that (1) German children show earlier emergence of organizational strategies than 
their American peers; (2) American children have higher, less-realistic academic self-concepts than the Germans; (3) American children in the mid-elementary grades tend to show a stronger attributional belief in the importance of effort in influencing achievement outcomes than Germans; and (4) relationships between attributions and achievement differ in the two countries. Whereas effort attributions predict laboratory task performance and school achievement for American children, ability attributions show a stronger relationship to the achievement of German children (Carr et al., 1989; Kurtz et al., 1989; Schneider et al., 1986).

We have hypothesized that the attribution and strategy differences found between American and German children are likely related to differences in the instructional practices and belief systems in the two countries. In this project, German and American teachers who were currently instructing Grades 1 through 4 completed questionnaires regarding their strategy and metacognitive instruction in the classroom as well as their attributional beliefs. Although the use of self-report data may lack validity compared to observational studies, we believed this would be a valuable and time-efficient preliminary step in measuring teachers' instructional practices and attributions (cf. Moely et al., 1989). Further, we made every effort to maximize the measurement validity of our teacher questionnaire through extensive pilot work.

Based on previous findings, we expected that German teachers would report more strategy instruction than American teachers, and that Americans would show relatively stronger effort attributions. Because Schneider et al. (1986) found a metacognitive advantage among American children, we anticipated that American teachers might report more metacognitive instruction related to executive processes such as general strategy knowledge, monitoring, and strategy modification. In a broader sense, we wanted to learn more about teachers' instruction in the two countries, particularly their explicit instruction of metacognitive information, and their responses to children's learning difficulties.

\section{METHOD}

\section{Subjects}

Fifty-nine teachers from West Germany and 43 teachers from the United States participated in the project. The German teachers were all recruited individually by phone, or by personal contacts in the schools where they worked. American teachers were recruited by phone or mail. Approximately $30 \%$ of the teachers contacted in the United States and $10 \%$ of the teachers contacted in W. Germany declined participation. Of the German teachers who participated, 30 were currently teaching either Grade 1 or 2 , and 29 were teaching Grade 3 or 4 . For the American teachers, 14 were instructing first or second grade, and 29 were instructing third or fourth grade.

American teachers were contacted from 13 schools in Texas, Rhode Island, Indiana, Michigan, and Illinois. Geographically, the sample represented a large city (Chicago), sub- 
urban areas, and small towns. The schools represented were both public and private (Catholic), and served families from working-, middle-, and upper-middle-class backgrounds. All participating German teachers worked in public schools in or immediately outside the $\mathrm{Ba}$ varian city of Munich. Although the German sample was more restricted geographically than the American sample, we felt that this group provided a reasonable representation of teaching practices in Bavaria, since school curriculum and teacher licensing requirements are established at a state level in Germany.

The German teachers had been teaching between 3 and 40 years, with an average classroom experience of 17.5 years $(S D=9.2)$. Two teachers in the Grade 3-4 group were male; all other German participants were female. The American teachers had been teaching between 1 and 33 years, for an average of 15.3 years $(S D=7.7)$. Sex of American participants was not recorded.

\section{Materials and Procedure}

The questionnaire consisted of seven questions inquiring about the classroom instruction of strategies and metacognitive skills, and four attribution questions about why children succeed and fail academically (see Appendix A). The questionnaire, which was an adapted and expanded version of a questionnaire used by Carr et al. (1989), was extensively pilottested to insure that the questions were accurately interpreted by teachers. Among the metacognitive and strategy questions, two asked about strategy utility information (Items 1 and 4); three measured teachers' awareness of and responsiveness to students' learning problems (Items 2, 5, and 7); one inquired about instruction of monitoring skills (Item 6); and one measured instruction of task-specific strategies (Item 3). The attribution questions were true or false items designed to measure teachers' beliefs about children's performances, pitting effort against ability explanations of children's achievement.

\section{Scoring}

Teachers completed the questionnaires alone and at their convenience, with a promise of anonymity. Scoring was conducted by two bilingual raters who first worked independently, arriving at a reliability level of $91 \%$, and then resolved differences together.

Items 1, 4, 5, and 6 had a two-point maximum. For Item 1, "Do you teach your students that different learning techniques are appropriate for different tasks? Please give some examples ... ," 2 points were awarded if teachers indicated that different tasks call for different strategies (for example: "I suggest that they not pay attention to names in a story when they are looking for main ideas," "Repetition is taught with math facts, SQ3R for reading"). One point was given to teachers who reported instructing children to use strategies, but failed to emphasize tailoring strategies to appropriate tasks. Teachers received zero points for this item if they answered in generalities such as "We use all the above."

Responses to Item 2a ("What specific learning problems do you encounter most often with children?"') were listed and then classified into closely related responses. As with the other items, two raters originally scored the items individually, then discussed their classification systems to resolve differences. One point was awarded for each mention of a learning problem, with a 1-point maximum for each response category, but no ceiling for total number of points. For Item $2 b$, "How do you handle these problems?," 1 point was awarded for each strategy used to treat the learning problems. No points were given for "solutions" to problems which that particular teacher had not mentioned as a probiem.

Item 3 ("Do you give your pupils instruction in the use of specific learning techniques? What strategies . . . do you teach in the following subject areas?") similarly had no ceiling. One point was awarded for each strategy mentioned that would be helpful to children. No points were awarded for task descriptions (e.g., comprehension) or for teaching strategies- 
that is, methods a teacher would employ herself, but not that children could use to increase their own learning efficiency (e.g., hands on; individual tutoring).

For Item 4 ("Do you tell your pupils in general terms that it helps to be strategic? Please give a few examples . . ."), 2 points were awarded for responses which explained the value of being strategic (e.g., it saves time; you can remember more and longer if you use strategies; doing this makes the work easier). One point was given for responses which mentioned strategies, but included no justification for their use (e.g., do the easy parts first, then the hard ones; find the main idea). Responses which made no reference to strategies or spoke only in generalities received zero points (e.g., we teach problem solving strategies; problems can be solved in more than one way).

Item 5 asked how the teacher would help a child who is having difficulty with an assignment that requires several steps. Two points were given for any reference to step-by-step problem solving with the child (e.g., help him do one step at a time; make a plan outline with the child; explain it step-by-step). One point was given for responses indicating individual work with the child or other useful strategies, but with no mention of a step-by-step procedure (e.g., ask the child to compare the required task to another assignment done successfully). Zero points were given for irrelevant responses (e.g., have them read the book).

For Item 6 ("A child appears to be very impulsive in completing schoolwork. . . What would you do?"'), 2 points were awarded for explanations to the child that reflective thinking leads to improved performance. For example, 2 points werc given for "Point out how careful reading will usually yield the correct answer" and "Discuss the problem, and then discuss the consequences." One point was given for responses that reinforced reflective thinking without explaining the value of it (e.g., have them slow down and do it over; remind him or her to think). No points were given for responses which made no reference to reflective thinking (e.g., re-do the work; discuss the matter with parents).

Item 7 ("Imagine that you have explained an arithmetic lesson, and the entire class fails to understand. What will you do next?") had a 1-point maximum. Teachers were given 1 point who indicated that they would explain the lesson again in another context, and/or using different materials. Zero points were given for reporting that the lesson would be repeated with no change.

For the four attribution items, 1 point was awarded for each response which indicated an attributional preference for effort; these scores were summed across items.

\section{RESULTS}

An alpha of .10 was chosen for all subsequent analyses to increase statistical power. Given the relatively small sample size and the fact that we anticipated a medium effect size $(E S=.25)$, the conventional alpha of .05 would have resulted in a low power level, that is, in only a .53 probability of rejecting the null hypothesis of no group differences. Liberalizing the alpha criterion to .10 raised the power level to an acceptable $71 \%$ (see Cohen, 1977).

\section{Strategy and Metacognitive Instruction}

Frequency distributions were computed for the number of years of teaching experience, and teachers were separated at the median-16 years-depending on how many years they had taught. Separate 2 (Country) $\times 2$ (Years of teaching) analyses of variance were conducted on the seven strategy and metacognitive scores. These analyses indicated that 
TABLE 1

German and American Teachers' Mean Responses by Item

\begin{tabular}{|c|c|c|c|c|}
\hline & \multicolumn{2}{|c|}{ United States } & \multicolumn{2}{|c|}{ W. Germany } \\
\hline & $\begin{array}{l}\text { Fewer } \\
\text { years }\end{array}$ & $\begin{array}{l}\text { More } \\
\text { years }\end{array}$ & $\begin{array}{l}\text { Fewer } \\
\text { years }\end{array}$ & $\begin{array}{l}\text { More } \\
\text { years }\end{array}$ \\
\hline $\begin{array}{l}\text { 1. Different learning techniques are } \\
\text { appropriate for different tasks. }^{a}\end{array}$ & $\begin{array}{l}.84 \\
(.80)^{b}\end{array}$ & $\begin{array}{l}.56 \\
(.71)\end{array}$ & $\begin{array}{l}.56 \\
(.80)\end{array}$ & $\begin{array}{l}.38 \\
(.71)\end{array}$ \\
\hline $\begin{array}{l}\text { 2. Name specific learning problems } \\
\text { you encounter in the classroom. }\end{array}$ & $\begin{array}{c}2.72 \\
(1.17)\end{array}$ & $\begin{array}{c}2.56 \\
(1.25)\end{array}$ & $\begin{array}{c}2.26 \\
(1.83)\end{array}$ & $\begin{array}{c}2.69 \\
(1.49)\end{array}$ \\
\hline $\begin{array}{l}\text { 3. Specific learning strategies you } \\
\text { instruct. }\end{array}$ & $\begin{array}{r}2.80 \\
(1.98)\end{array}$ & $\begin{array}{l}3.00 \\
(2.61)\end{array}$ & $\begin{array}{l}4.33 \\
(3.15)\end{array}$ & $\begin{array}{l}3.75 \\
(2.47)\end{array}$ \\
\hline $\begin{array}{l}\text { 4. Do you tell your students in general } \\
\text { terms the value of being strategic? }\end{array}$ & $\begin{array}{l}.52 \\
(.65)\end{array}$ & .44 & $\begin{array}{l}.52 \\
(.75)\end{array}$ & $\begin{array}{l}.56 \\
(.71)\end{array}$ \\
\hline $\begin{array}{l}\text { 5. How do you help a child with an } \\
\text { assignment requiring several steps? }\end{array}$ & $\begin{array}{l}1.84 \\
(.47)\end{array}$ & $\begin{array}{l}1.28 \\
(.83)\end{array}$ & $\begin{array}{l}1.41 \\
(.80)\end{array}$ & $\begin{array}{l}1.22 \\
(.71)\end{array}$ \\
\hline 6. How do you help an impulsive child? & $\begin{array}{l}.48 \\
(.71)\end{array}$ & $\begin{array}{l}.61 \\
(.78)\end{array}$ & $\begin{array}{l}.26 \\
(.45)\end{array}$ & $\begin{array}{l}.31 \\
(.54)\end{array}$ \\
\hline $\begin{array}{l}\text { 7. Your entire class fails to understand } \\
\text { a lesson. }\end{array}$ & $\begin{array}{l}.88 \\
(.33)\end{array}$ & $\begin{array}{l}.78 \\
(.43)\end{array}$ & $\begin{array}{l}.82 \\
(.40)\end{array}$ & $\begin{array}{l}.84 \\
(.37)\end{array}$ \\
\hline Total & $\begin{array}{l}10.08 \\
(3.34)\end{array}$ & $\begin{array}{c}9.22 \\
(4.07)\end{array}$ & $\begin{array}{l}10.15 \\
(3.84)\end{array}$ & $\begin{array}{c}9.75 \\
(4.40)\end{array}$ \\
\hline Summed effort attributions & $\begin{array}{c}3.79 \\
(.42) \\
n=25\end{array}$ & $\begin{array}{c}3.78 \\
(.43) \\
n=18\end{array}$ & $\begin{array}{c}3.10 \\
(.72) \\
n=27\end{array}$ & $\begin{array}{c}3.33 \\
(.92) \\
n=32\end{array}$ \\
\hline
\end{tabular}

${ }^{a}$ Questions are paraphrased. See Appendix A for actual items.

${ }^{b}$ Standard deviations appear in parenthesis.

teachers who had taught less than 16 years reported more explanation of the usefulness of breaking tasks down into component parts (Item 5) than teachers who had taught longer, $F(1,98)=6.0$, that German teachers reported more task-specific strategy instruction than U.S. teachers (Item $3), F(1,98)=6.2$, and that U.S. teachers reported more metacognitively enriched guidance to impulsive children (Item 6) and more task analysis instruction (Item 5) than did German teachers $F(1,98)=4.3$ and 3.3, respectively. All other effects were nonsignificant. Means and standard deviations are reported by item in Table $1 .^{1}$

A 2 (Country) $\times 2$ (Years) analysis of variance on summed scores across the general metacognitive items (i.e., all items except Item 3, the strategy-specific question) was significant, indicating that American teachers $(M=6.84)$ scored higher than German teachers $(M=5.92)$,

${ }^{1}$ Although scores on individual items were not always normally distributed, these analyses were justified because analysis of variance is robust against violations of normality assumptions when samples are of reasonable size and group sizes are approximately equal (Keppel, 1973). 
$F(1,98)=3.3$. Correlations between Item 3 and the summed scores across all other items were significant for both German and American teachers, $r(58)=.42$ and $r(42)=.38$, respectively.

Frequency counts were calculated for responses to Item 2 (see Table 2). The most frequent learning problems reported by teachers in both countries were distractibility and lack of motivation. Fifty-two of the 102 teachers reported that children were often distracted and had problems concentrating; 17 teachers reported that lack of motivation was a problem. Other frequent responses for U.S. teachers were immaturity or discipline problems $(n=12)$, and a deficient home environment $(n=9)$. Ten German teachers reported that children had problems learning in their classes because they were at different instructional levels.

Teachers' reports of task-specific strategy instruction (Item 3) were first classified into related categories, then coded with frequency counts. Our aim was to simplify the number of strategies reported without losing too much detail. The final categories appear in Table 3. The most frequent strategies reported by American teachers were identifying the main points-including underlining, note-taking, and outlining $(n=26)$; checking or monitoring $(n=22)$; and using external, concrete aids to learning $(n=22)$. German teachers most frequently reported instruction of phonetic strategies such as sounding out, lengthening words, or finding root words in order to identify meaning $(n=50)$; recoding of information to aid learning or problem solving $(n=36)$; external aids $(n=34)$; relating new information to previously learned material, finding patterns and analogies $(n=32)$; and elaboration $(n=22)$.

TABLE 2

Learning Problems Named by German and U.S. Teachers

\begin{tabular}{lrr}
\hline & U.S. & German \\
\hline $\begin{array}{l}\text { Distractibility (too much off-task behavior, short attention span, } \\
\text { poor listening skills) }\end{array}$ & 19 & 33 \\
$\begin{array}{l}\text { Avoidance, lack of motivation, no pride in work, laziness } \\
\text { Immaturity, behavior/discipline problems, emotional problems }\end{array}$ & 11 & 6 \\
$\begin{array}{l}\text { Too little academic work at home, too much TV, deficient home } \\
\text { environment (sleep, food, etc.) }\end{array}$ & 9 & 5 \\
$\begin{array}{l}\text { Reading below grade level, poor math concepts (children cannot } \\
\text { follow lessons because they are at different levels) }\end{array}$ & 2 & 10 \\
Low mental ability & 4 & 7 \\
$\begin{array}{l}\text { Poor organization } \\
\text { Don't read directions }\end{array}$ & 4 & 1 \\
$\begin{array}{l}\text { Impulsivity, hurrying through work } \\
\text { Difficulty in transfering learning }\end{array}$ & 4 & 1 \\
Other: auditory or visual problems, fine motor skills, lack of & 3 & 2 \\
$\quad$ confidence, passivity, poor attendance & 0 & 3 \\
\hline
\end{tabular}


TABLE 3

Teachers' Task-Specific Strategy Instruction

\begin{tabular}{|c|c|c|c|c|}
\hline \multirow[b]{2}{*}{ Strategy } & \multicolumn{2}{|c|}{ United States } & \multicolumn{2}{|c|}{ W. Germany } \\
\hline & $\begin{array}{l}\text { Fewer } \\
\text { years }\end{array}$ & $\begin{array}{l}\text { More } \\
\text { years }\end{array}$ & $\begin{array}{l}\text { Fewer } \\
\text { years }\end{array}$ & $\begin{array}{l}\text { More } \\
\text { years }\end{array}$ \\
\hline $\begin{array}{l}\text { 1. Identifying main points; underlining; } \\
\text { note-taking; outlining }\end{array}$ & 19 & 7 & 13 & 5 \\
\hline 2. Rote learning; drilling; rehearsal & 5 & 2 & 7 & 6 \\
\hline $\begin{array}{l}\text { 3. Relating new to old information; } \\
\text { finding patterns; analogies }\end{array}$ & 9 & 7 & 20 & 12 \\
\hline $\begin{array}{l}\text { 4. Recoding of information; breaking tasks } \\
\text { down into steps; organization }\end{array}$ & 8 & 9 & 20 & 16 \\
\hline 5. Elaboration & 0 & 4 & 11 & 11 \\
\hline $\begin{array}{l}\text { 6. Monitoring performance; checking; } \\
\text { using context }\end{array}$ & 10 & 12 & 3 & 7 \\
\hline $\begin{array}{l}\text { 7. External, concrete aids; covering lines; } \\
\text { glossaries; dictionaries; counters; fingers }\end{array}$ & 13 & 9 & 15 & 19 \\
\hline $\begin{array}{l}\text { 8. Sounding out; using phonetic rules; } \\
\text { lengthening words, finding root words; } \\
\text { reading aloud }\end{array}$ & 1 & 3 & 21 & 29 \\
\hline 9. Skimming; finding gist & 2 & 0 & 3 & 2 \\
\hline 10. Other & $\begin{array}{c}3 \\
n=25\end{array}$ & $\begin{array}{c}1 \\
n=18\end{array}$ & $\begin{array}{c}4 \\
n=27\end{array}$ & $\begin{array}{c}13 \\
n=32\end{array}$ \\
\hline
\end{tabular}

We conducted 2 (Country) $\times 2$ (Years) analyses of variance on scores from the first eight strategy categories depicted in Table 3 . As the last two strategy categories depicted in this table were rarely used by American teachers, statistical analyses on these items did not seem warranted. Analyses on the first eight categories indicated that German teachers were more likely than American teachers to instruct elaboration, phonetic strategies, and strategies related to the recoding of information in order to simplify tasks, $F(1,98)-5.8,25.8$, and 3.6 , respectively. American teachers reported more instruction of checking and of searching for main points than did the Germans, $F(1,98)=9.9$ and 3.3 , respectively. Teachers who had taught fewer than 16 years (versus longer than 16 years) reported more instruction of main points than did their counterparts, $F(1,98)=6.1$. All other effects were nonsignificant.

In order to gain a clearer picture of the quality of teachers' responses, frequency counts were conducted for teachers' scores by item. Those results are reported in Table 4 . As can be seen, a very small percentage of teachers gave "metacognitively informed" responses, particularly for Items 4 and 6. A surprisingly high percentage of American teachers (approximately $23 \%$ ) either reported no task-specific strategy instruction, or else named only one strategy. 
TABLE 4

Percentages of Teacher Responses to Strategy Questions

\begin{tabular}{|c|c|c|c|c|c|}
\hline \multirow[b]{2}{*}{ Item } & \multirow[b]{2}{*}{$\begin{array}{l}\text { No. of } \\
\text { points }\end{array}$} & \multicolumn{2}{|c|}{ U.S. } & \multicolumn{2}{|c|}{ German } \\
\hline & & $\begin{array}{l}\text { Fewer } \\
\text { years }\end{array}$ & $\begin{array}{l}\text { More } \\
\text { years }\end{array}$ & $\begin{array}{l}\text { Fewer } \\
\text { years }\end{array}$ & $\begin{array}{l}\text { More } \\
\text { years }\end{array}$ \\
\hline \multirow[t]{3}{*}{1} & 0 & 40 & 56 & 63 & 75 \\
\hline & 1 & 36 & 33 & 19 & 13 \\
\hline & 2 & $24^{a}$ & 11 & 19 & 13 \\
\hline \multirow[t]{3}{*}{2} & 0 or 1 & 16 & 11 & 37 & 16 \\
\hline & 2 or 3 & 52 & 67 & 37 & 53 \\
\hline & 4 or more & 32 & 22 & 26 & 31 \\
\hline \multirow[t]{4}{*}{3} & 0 or 1 & 20 & 28 & 7 & 13 \\
\hline & 2 or 3 & 52 & 44 & 30 & 38 \\
\hline & 4 or 5 & 20 & 17 & 33 & 34 \\
\hline & 6 or more & 8 & 11 & 30 & 16 \\
\hline \multirow[t]{3}{*}{4} & 0 & 56 & 56 & 63 & 62 \\
\hline & 1 & 36 & 44 & 22 & 1 \\
\hline & 2 & 8 & 0 & 15 & 19 \\
\hline \multirow[t]{3}{*}{5} & 0 & 4 & 22 & 18 & 16 \\
\hline & 1 & 8 & 28 & 22 & 47 \\
\hline & 2 & 88 & 50 & 59 & 38 \\
\hline \multirow[t]{3}{*}{6} & 0 & 64 & 56 & 74 & 72 \\
\hline & 1 & 24 & 28 & 26 & 25 \\
\hline & 2 & 12 & 17 & 0 & 3 \\
\hline \multirow[t]{3}{*}{7} & 0 & 12 & 22 & 18 & 16 \\
\hline & 1 & 88 & 78 & 82 & 84 \\
\hline & & $n=25$ & $n=18$ & $n=27$ & $n=32$ \\
\hline
\end{tabular}

${ }^{a}$ Because of rounding error, percentages may not add up to 100 .

\section{Teachers' Attributions about Children's Achievement}

As reported above, responses to the attribution items which indicated a preference for effort were summed across the four items to yield a single attribution score for each teacher. One American teacher and 12 German teachers failed to respond to one or more of the attribution items; these teachers were dropped from the analyses. A 2 (Country) $\times 2$ (Years) ANOVA on effort attribution scores indicated that U.S. teachers showed a stronger preference toward effort than did German teachers, $F(1,85)=$ 15.4. The main effect of Years and the Country $\times$ Years interaction were nonsignificant. Correlations between effort attributions and strategy instruction (Item 3 ) and between effort attributions and general metacognitive instruction were nonsignificant. 


\section{DISCUSSION}

The results of this study provided tentative support for our hypotheses regarding the role of instructional variables in contributing to interindividual differences in children's strategy use and attributional beliefs, and also provided new evidence about classroom metacognitive instruction in West Germany and the United States. Cross-cultural differences found previously between German and American children paralleled differences in the present study between the reported instructional practices of teachers in the two countries. Although German teachers reported more instruction of task-specific strategies, American teachers reported more metacognitive guidance to impulsive children than did German teachers, and also reported more instruction of monitoring. Furthermore, American teachers reported stronger effort attributions than did the German teachers, corresponding to attributional differences found previously among children and parents in the two countries (Carr et al., 1989; Kurtz et al., 1989).

\section{Metacognitive and Strategic Instruction}

Overall, the amount of metacognitive and strategy instruction reported was disappointing. For example, $23 \%$ of American teachers reported either no instruction of task-specific strategies, or named only one strategy. Likewise, although German teachers reported more instruction of taskspecific strategies, their reports of metacognitive instruction such as monitoring and the utility of strategies were poor: only 1 of 59 German teachers reported giving a metacognitive explanation to impulsive children about the values of working reflectively.

Pressley and his colleagues have recently listed several obstacles to good strategy instruction (Pressley et al., 1989). For instance, (1) teachers may not be adequately educated regarding information processing theory; (2) teachers may already have too many demands placed on them within the instructional setting; (3) interindividual differences among children complicate strategy instruction, which should ideally be tailored to each child; and (4) teachers often lack evaluative data regarding effective strategy instruction (Pressley et al., 1989). Our data support some of these tenets: in addition to reporting little metacognitive or strategy instruction, both German and American teachers in the present study seemed to focus more on noncognitive learning problems such as distractibility or emotional problems rather than on cognitive skills problems.

Encouragingly, there was a slight tendency for younger teachers in both countries to report more strategy and metacognitive instruction than older teachers. Teachers who had taught fewer than the median number of years reported more instruction of strategies such as identifying main 
points, underlining, and note-taking. These data might reflect the increased awareness in the past two decades of the need for instruction in information processing theory in departments of education. The superior strategy instruction of the less experienced teachers brightens a rather pessimistic picture regarding teachers' current levels of strategy and metacognitive instruction.

\section{Environmental Influences on Children's Development}

Although the responsibility for children's education is shared by parents and teachers, the education of our children has moved increasingly away from the home and into the school during the past century (Coleman, 1987). As primary agents in children's lives, teachers have profound impacts on children's cognitive, social, and emotional development. The results of the present study point to some specific ways in which teachers affect the development of children's metacognitive and strategic knowledge. The superior task-specific strategy instruction of German teachers in the present study corresponds to earlier results indicating earlyemerging strategy use and associated performance gains in German elementary school children (Carr et al., 1989; Schneider et al., 1986). Thus, the superior strategy use of German children may be due to the stronger emphasis on strategy deployment in German classrooms. Since the differential treatment of students within classrooms affects student-teacher interactions and children's ensuing performances, it is not surprising that cross-cultural differences in metacognitive and strategy instruction would be reflected in differences in actual strategy use and attributional beliefs (Marshall \& Weinstein, 1986; Peterson, 1988; Rogoff \& Mistry, 1985).

Although "culture" is a global factor that is too general to be of much explanatory value, cross-cultural research is nonetheless a valuable tool in understanding contrasts in children's performances and development, as those differences are tied to culturally related factors such as language, educational systems, and economic conditions (Kurtz, 1990). For example, in contrast to American teachers, German teachers reported instruction of many more strategies related to phonetics, including sounding out words, reading aloud, and lengthening or shortening words to aid comprehension. Differences between the German and English languages probably account for most of this difference in instructional practices. Similarly, American teachers' higher effort attributions reflect the orientation of the American culture toward hard work as a means of success. In the United States, a belief in personal effort is related to persistence on challenging tasks, and effort attributions are believed to be instrumental in the acquisition and deployment of metacognition and strategies (Dweck \& Elliot, 1983; Pressley, Cariglia-Bull, Deane, \& Schneider, 1987b). 
However, it is likely that in addition to cultural differences in these belief patterns, there are also differences in the ways these beliefs influence performance. We have recently found that a strong attributional belief in effort is related to school achievement for American children, but not for German children (Kurtz et al., 1989).

On the one hand, the negative results of the present research must be interpreted with caution, since our data were based on self-report rather than direct observation and therefore may have been subject to measurement problems such as lack of interest on the part of questionnaire respondents, or a misunderstanding of the questions. The apparent lack of strategy instruction in the classroom, however, corresponds to results of previous research using observational methods. For instance, when observing 69 teachers for $30 \mathrm{~min}$ per day over 5 days, Moely et al. (1986a) observed less than four strategy suggestions per teacher. Furthermore, rationales for strategy use were given only about one-third of the time. The message seems clear: Teachers need to be encouraged and instructed to use strategy-based instruction, with increasing frequency, precision, and creativity.

\section{APPENDIX A}

1. Do you teach your students that different learning techniques (e.g., repetition, grouping, studying the main points) are appropriate for different tasks?

$$
\text { always often sometimes seldom never }
$$

Please give examples of instruction you give your pupils regarding the above.

2. What specific learning problems do you encounter most often with children (including child behaviors that interfere with efficient learning)?

How to you handle these problems?

3. Do you give your students instruction in the use of specific learning strategies? What strategies or special learning techniques do you teach in the following subject areas? Math, reading, other subjects:

4. Do you ever tell your students in general terms that is helps to be strategic?

$$
\text { always often sometimes seldom never }
$$

If so, please give a few examples of what you say to your students.

5. A child is having difficulty with an assignment that requires several steps, for example, preparing a book report. How would you help the child?

6. A child appears to be very impulsive in completing schoolwork. She doesn't seem to think about the task requirements, and answers questions without thinking. What would you do?

7. Imagine that you have explained an arithmetic lesson, and nearly the entire class fails to understand. What will you do next?

What do you think of the following statements? 
8. If a child in your class is average in ability and achievement, it is possible for him to work very hard, and in 2 years be one of the best in his class in terms of grades.

true false

9. I have had students in my class who were very capable, but performed poorly. If these students had tried harder, they could have dramatically improved their academic records. true false

10. I have had students in my class who were not very talented, but who performed at a high level only because they worked very hard.

true false

11. Imagine that two students in your class are performing approximately equivalently on their schoolwork. However, student A, whom you judge to be very bright, is not working very hard. Student B is not so capable, but works very hard. Which student do you think is the most likely to succeed in the long run?

Student A Student B

\section{REFERENCES}

Borkowski, J. G., Carr, M., Rellinger, E., \& Pressley, M. (in press). Self-regulated cognition: Interdependence of metacognition, attributions, and self-esteem. In B. F. Jones \& L. Idol (Eds.), Dimensions of thinking and cognitive instruction. Chicago: Association for Supervision and Curriculum Development.

Byro, D. M., \& Gholson, B. (1985). Reading, memory, and metacognition. Journal of Educational Psychology, 77, 428-436.

CARR, M., \& KurTz, B. E. (1989). Teachers' perceptions of their students' metacognition, attributions, and self-concept. Manuscript submitted for publication.

Carr, M., Kurtz, B. E., Schneider, W., Turner, L. A., \& Borkowski, J. G. (1989). Strategy acquisition and transfer among American and German children: Environmental influences on metacognitive development. Developmental Psychology, 25, 765-771.

CoHen, J. (1977). Statistical power analyses for the behavioral sciences. New York: Academic Press.

Cole, M. (1988). Cross-cultural research in the sociohistorical tradition. Human Development, 31, 137-157.

Coleman, J. S. (1987). Families and schools. Educational Researcher, 16, 32-38.

Crano, W., \& Mellon, P. (1978). Causal influence of teachers' expectations on children's academic performance: A cross-lagged panel analysis. Journal of Educational Psychology, 70, 39-49.

Dweck, C. S., \& Elliott, E. S. (1983). Achievement motivation. In P. Mussen \& E. M. Heatherington (Eds.), Handbook of child psychology (Vol. 3, pp. 643-691). New York: Wiley.

Grant, L., \& Rothenberg, J. (1986). The social enhancement of ability differences: Teacher-student interactions in first- and second-grade reading groups. The Elementary School Journal, 87, $29-49$.

Holloway, S. D. (1988). Concepts of ability and effort in Japan and the United States. Review of Educational Research, 58, 327-345.

Justice, E. M. (1985). Categorization as a preferred memory strategy: Developmental changes during elementary school. Developmental Psychology, 21, 1105-1110.

KePPEL, G. (1973). Design and analysis: A researcher's handbook. Englewood Cliffs, NJ: Prentice Hall.

Kreutzer, M. A., Leonard, C., \& Flavell, J. H. (1975). An interview study of chil- 
dren's knowledge about memory. Monographs of the Society for Research in Child Development, 40 (Serial No. 159).

KuRTz, B. E. (1990). Cultural influences on children's cognitive and metacognitive development. In W. Schneider \& F. E. Weinert (Eds.), Interactions among aptitudes, strategies, and knowledge in cognitive performance (pp. 177-199). New York: Springer Verlag.

Kurtz, B. E., Schneider, W., Borkowski, J. G., CARr, M., \& Turner, L. (1989). The development of attributions, self-concept, and achievement in German and American children. Manuscript submitted for publication.

Marshall, H. H., \& Weinstein, R. S. (1986). Classroom context of student-perceived differential teacher treatment. Journal of Educational Psychology, 78, 441-453.

Moely, B. E., Hart, S. S., Leal, L., Johnson-Baron, T., Santulli, K. A., \& Rao, N. (1986a, April). An investigation of how teachers establish stable use and generalization of memory strategies through the use of effective training techniques. Paper presented at the annual meetings of the American Educational Research Association, San Francisco.

Moely, B. E., Hart, S. S., Santulli, K., Leal, L., Johnson, T., Rao, N., \& Burney, L. (1986b). How do teachers teach memory skills? Educational Psychologist, 21, 55-71.

Moely, B. E., Hart, S. S., Santulli, K. A., Leal, L., Kogut, D. J., Mclain, E., Zhou, Z., \& Johnson, T. D. (1989, April). Teachers' cognitions about the memory processes of elementary school children: A developmental perspective. Paper presented at the biennial meetings of the Society for Research in Child Development, Kansas City.

Moely, B. E., Leal, L., Pechman, E. M., Johnson, T. D., Santulli, K. A., Rao, N., HART, S. S., \& BURNEY, L. (1986c, March). Relationships between teachers' cognitive instruction and children's memory skills. Paper presented at the meeting of the Southwestern Society for Research in Child Development, San Antonio, TX.

Moely, B. E., Santulli, K. A., \& RaO, N. (1985). Teachers' expectations for memory and metamemory skills of elementary school children. Paper presented at the biennial meetings of the Society for Research in Child Development, Toronto.

Myers, M., \& PARIS, S. G. (1978). Children's metacognitive knowledge about reading. Journal of Educational Psychology, 70, 680-690.

NeimarK, E. D. (1976). The natural history of spontaneous mnemonic activities under conditions of minimal experimental constraint. In A. D. Pick (Ed.), Minnesota symposia on child psychology (Vol. 10). Minneapolis: University of Minnesota Press.

Ornstein, P. A., Baker-WARd, L., \& NaUs, M. J. (1989). The development of mnemonic skill. In F. E. Weinert \& M. Perlmutter (Eds.), Memory development: Universal changes and individual differences (pp. 31-50). Hillsdale, NJ: Erlbaum.

Parsons, J. E., Kaczala, C. M., \& Meece, J. L. (1982). Socialization of achievement attitudes and beliefs: Classroom influences. Child Development, 53, 322-339.

Peterson, P. L. (1988). Teachers' and students' cognitional knowledge for classroom teaching and learning. Educational Researcher, 17, 5-14.

Pressley, M. (1982). Elaboration and memory development. Child Development, 53, 296309.

Pressley, M., Borkowski, J. G., \& Schneider, W. (1987a). Good strategy users coordinate metacognition, strategy use, and knowledge. In R. Vasta \& G. Whitchurst (Eds.), Annals of child development (Vol. 4, pp. 89-129). Greenwich, CT: JAI Press.

Pressley, M., Cariglia-Bull, T., Deane, S., \& Schneider, W. (1987b). Short-term memory, verbal competence, and age as predictors of imagery instructional effectiveness. Journal of Experimental Child Psychology, 43, 194-211. 
Pressley, M., Goodchild, F., Fleet, J., Zajchowski, R., \& Evans, E. D. (1989). The challenges of classroom strategy instruction. The Elementary School Journal, 89, 301342.

Rogoff, B., \& Mistry, J. J. (1985). Memory development in cultural context. In M. Pressley \& C. Brainerd (Eds.), Cognitive learning and memory in children (pp. 117-142). New York: Springer Verlag.

SCHNEIDER, W. (1985). Developmental trends in the metamemory-memory behavior relationship: An integrative review. In D. L. Forrest-Pressley, G. E. McKinnon, \& T. G. Waller (Eds.), Cognition, metacognition, and performance (pp. 57-109). New York: Academic Press.

Schneider, W., Borkowski, J. G., Kurtz, B. E., \& Kerwin, K. (1986). Metamemory and motivation: A comparison of strategy use and performance in German and American children. Iournal of Cross-Cultural Psychology, 17, 315-336.

Schneider, W., \& Pressley, M. (1989). Memory development between 2 and 20. New York: Springer Verlag.

Stevenson, H. W. (1988). Culture and schooling: Influences on cognitive development. In E. M. Hetherington, R. Lerner, \& M. Perlmutter (Eds.), Child development and a life-span perspective (pp. 241-258). Hillsdale, NJ: Erlbaum.

Wagner, D. A., \& Paris, S. G. (1981). Problems and prospects in comparative studies of memory. Human Development, 24, 412-424. 